\title{
Dermatomyositis as a complication of interferon- $\alpha$ therapy: a case report and review of the literature
}

\author{
Hideyuki Shiba $\cdot$ Tohru Takeuchi $\cdot$ Kentaro Isoda $\cdot$ \\ Yasuhito Kokunai · Yumiko Wada · Shigeki Makino • \\ Toshiaki Hanafusa
}

Received: 15 January 2014 / Accepted: 3 March 2014 / Published online: 18 March 2014

(c) The Author(s) 2014. This article is published with open access at Springerlink.com

\begin{abstract}
Autoimmune disorder is one of the important side effects of interferon- $\alpha$ therapy. Some polymyositis cases as complication of interferon- $\alpha$ therapy were reported, but dermatomyositis were rarely. We report a case of dermatomyositis as a complication of interferon- $\alpha$ therapy for hepatitis C. A 52-year-old Japanese man was treated by combination therapy with pegylated interferon- $\alpha-2 b$ and ribavirin for hepatitis $\mathrm{C}$. Three months after the initiation of therapy, he showed erythema in the posterior cervical to dorsal and anterior cervical to thoracic regions, weight loss, general malaise, muscle pain, and severe increase in levels of muscle enzymes. We made a diagnosis of dermatomyositis according to these clinical features, proximal muscle-predominant myogenic change on electromyography, and infiltration of monocytes and CD4+-dominant lymphocytes on skin biopsy, although myositis-associated antibodies were absent. He was successfully treated with intravenous immunoglobulin and tacrolimus in addition to glucocorticoid. This is a very rare case of dermatomyositis associated with interferon- $\alpha$ therapy. We reviewed several similar published cases and the association of dermatomyositis and type I interferon.
\end{abstract}

Keywords Dermatomyositis - Polymyositis . Interferon- $\alpha \cdot$ Hepatitis $C \cdot$ Tacrolimus

H. Shiba $\cdot$ T. Takeuchi $\cdot$ K. Isoda $(\bowtie) \cdot$ Y. Wada $\cdot$ S. Makino $\cdot$

T. Hanafusa

Department of Internal Medicine (I), Osaka Medical College, Daigaku-Machi 2-7, Takatsuki, Osaka 569-8686, Japan

e-mail: in1317@poh.osaka-med.ac.jp

Y. Kokunai

Department of Dermatology, Osaka Medical College,

Takatsuki, Osaka, Japan

\section{Introduction}

Polymyositis (PM) and dermatomyositis (DM) are autoimmune muscle disorders that symmetrically affect primarily the proximal limbs, neck, and pharyngeal muscles. DM is accompanied by a characteristic rash such as Gottron's papules and heliotrope rash of the eyelids. CD4+ T cells, CD8+ T cells, macrophages, and dendritic cells infiltrate around muscular tissue and blood vessels with degeneration and regeneration of muscular fibers. Inflammatory cytokines such as TNF- $\alpha$, IL-1, IL-6, IL-15, and IL-18 are thought to play a crucial role in the pathogenesis of $\mathrm{PM} / \mathrm{DM}[1]$.

Type I interferon (IFN) is a giant cytokine family including IFN- $\alpha$, IFN- $\beta$, IFN- $\omega$, IFN- $\lambda$, and IFN- $\tau$. These cytokines have antiviral and antitumor activities. IFN$\alpha$ and IFN- $\beta$ are used to treat viral hepatitis or malignant melanoma. Furthermore, the efficacy of IFN- $\beta$ for multiple sclerosis was also demonstrated [2]. However, several studies reported that autoimmune diseases such as systemic lupus erythematosus and PM/DM can develop during treatment with IFN- $\alpha$ or IFN- $\beta$ [3-14]. We report a patient who developed DM as a complication of IFN- $\alpha$ therapy for hepatitis C. In this patient, dermatomyositis was rapidly progressive and successfully treated with glucocorticoid therapy in addition to intravenous immunoglobulin (IVIG) and tacrolimus without reactivation of the hepatitis $C$ virus.

\section{Case report}

A 52-year-old man was diagnosed as being a hepatitis C virus (HCV, Genotype 1) carrier in 1997, but he was not treated. He sought medical advice in regard to hepatitis at a hospital. Combination therapy with weekly subcutaneous 
Fig. 1 a Erythema on the posterior cervical region. $\mathbf{b}, \mathbf{c}$ Monocytes and lymphocytes infiltrate around blood vessels in the superficial corium layer and in the middle to deep layers of the corium. (b H\&E, $\times 40)(\mathbf{c}$ H\&E, $\times 400)$ d and e Lymphocytes stained with CD4 infiltrate into the perivascular region more than those with CD8. (d immunostaining for CD4, $\times 400$ ) (e immunostaining for $\mathrm{CD} 8, \times 400)$
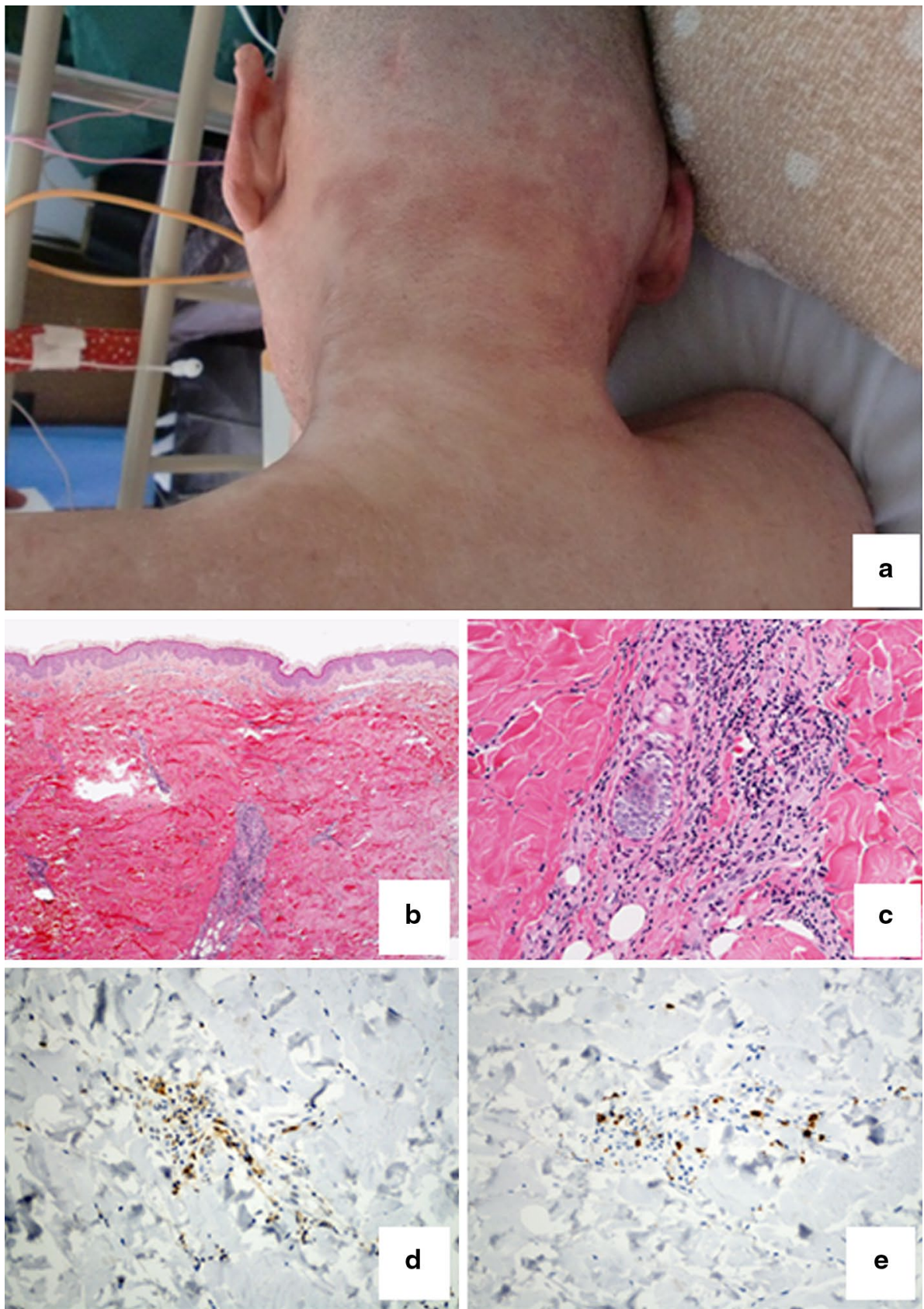

injection of pegylated IFN- $\alpha-2 b$ (PEG-IFN- $\alpha-2 b) 100 \mathrm{mg} /$ body and oral administration of ribavirin $800 \mathrm{mg} /$ day were initiated in June 2011. Erythema involving the cervical and dorsal regions appeared, and weight loss was noted 3 months after the initiation of therapy. In January 2012, exacerbation of the erythema, general malaise, muscular pain, and a severe increase in the level of creatine kinase (CK) 23-36,500 U/l were observed. Therefore, PEGIFN- $\alpha-2 b$ and ribavirin were discontinued, and the patient was admitted to our hospital. Heliotrope rash on the eyelids, shawl sign, and protruding and purple-red erythema (Fig. 1) were present on the posterior cervical to dorsal and anterior cervical to thoracic regions. Proximal upper limb-dominant muscular weakness of the cervical flexors and deltoid muscle and decreased grip strength were also observed. The blood examination showed increased levels of CK $(29,333 \mathrm{U} / \mathrm{l})$, aldolase (288.8 U/l), C-reactive protein $(3.94 \mathrm{mg} / \mathrm{dl})$, aspartate aminotransferase $(1,106 \mathrm{U} / \mathrm{l})$, alanine aminotransferase $(1,171 \mathrm{U} / \mathrm{l})$, and lactate dehydrogenase $(1,709 \mathrm{U} / \mathrm{l})$. The thyroid function was normal. Positive levels of antinuclear antibody (1:640, speckled pattern) were detected. Anti-aminoacyl tRNA synthetase (ARS), anti-signal recognition particle, anti-Mi-2 antibody, anti-PM/SCL antibody, anti-MDA5 antibody, 
Table 1 DM and PM associated with IFN alpha therapy

\begin{tabular}{|c|c|c|c|c|c|c|c|c|c|}
\hline Ref & $\mathrm{DM}$ or $\mathrm{PM}$ & Age/sex & Disease & IFN & Latency & Autoantibodies & IP & Treatment & Outcome \\
\hline [3] & $\mathrm{DM}$ & $62 / \mathrm{F}$ & Hepatitis C & PEG-IFN- $\alpha-2 b$ & 2 weeks & Anti-PL-7 Ab, ANA & + & PDN, IVIG & Improved \\
\hline [4] & $\mathrm{DM}$ & $57 / \mathrm{F}$ & Malignant melanoma & IFN- $\alpha$ & 6 weeks & Anti-Jo-1 Ab & + & DEX, MTX & Improved \\
\hline [5] & $\mathrm{PM}$ & $50 / \mathrm{F}$ & Hepatitis C & PEG-IFN- $\alpha$ & 2 months & None & ND & PDN & Improved \\
\hline [6] & PM & $54 / \mathrm{M}$ & Hepatitis C & IFN- $\alpha-2 b$ & $3-4$ months & $\begin{array}{l}\text { Anti-thyroglobulin } \\
\text { Ab, Anti- } \\
\text { microsome Ab }\end{array}$ & ND & None & Improved \\
\hline [7] & $\mathrm{PM}$ & $47 / \mathrm{M}$ & Hepatitis C & IFN- $\alpha$ & 2 months & ANA & ND & PDN, steroid pulse & Improved \\
\hline [8] & $\mathrm{PM}$ & $51 / \mathrm{M}$ & Hepatitis C & IFN- $\alpha-2 b$ & 6 months & ND & $\mathrm{ND}$ & ND & Improved \\
\hline [9] & $\mathrm{PM}$ & $33 / \mathrm{M}$ & Hepatitis B & IFN- $\alpha$ & 6 weeks & None & $\mathrm{ND}$ & PDN, IVIG & Improved \\
\hline [10] & PM & $50 / \mathrm{F}$ & $\begin{array}{l}\text { Essential thrombocy- } \\
\text { tosis }\end{array}$ & IFN- $\alpha-2 b$ & 2 months & None & ND & PDN, IVIG & Improved \\
\hline$[11]$ & PM & $48 / \mathrm{F}$ & Malignant melanoma & IFN- $\alpha$ & 7 months & $\begin{array}{l}\text { Anti-thyroglobulin } \\
\text { Ab, Anti- } \\
\text { peroxidase Ab }\end{array}$ & ND & PDN, steroid pulse & Improved \\
\hline [12] & PM & $24 / \mathrm{M}$ & $\begin{array}{l}\text { Chronic myeloid } \\
\text { leukemia }\end{array}$ & IFN- $\alpha$ & ND & None & ND & MPDN & Improved \\
\hline Ours & DM & $52 / \mathrm{M}$ & Hepatitis C & PEG-IFN- $\alpha-2 b$ & 3 months & ANA & - & PDN, IVIG, TAC & Improved \\
\hline
\end{tabular}

Ref reference, $D M$ dermatomyositis, $P M$ polymyositis, $M$ male, $F$ female, $P E G$ pegylated, $I F N$ interferon, $A b$ antibodies, $A N A$ anti-nuclear antibodies, $P D N$ prednisolone, $M P D N$ methylprednisolone, $D E X$ dexamethasone, MTX methotrexate, TAC tacrolimus, IVIG intravenous immunogloblin, $N D$ not described, $I P$ interstitial pneumonia

anti-ribonucleoprotein antibody, anti-double stranded DNA antibody, and other disease-specific autoantibodies were negative. Complement level was normal. Electromyography showed proximal muscle-predominant myogenic changes. Magnetic resonance imaging of upper limbs showed diffuse myopathy. A skin biopsy showed infiltration of monocytes and CD4+-dominant lymphocytes around blood vessels in the superficial corium layer and in the middle to deep layers of the corium (Fig. 1). Although a muscle biopsy was not performed because of the patient's non-consent, based on these findings, a diagnosis of DM was made [3, 4], and prednisolone $80 \mathrm{mg} /$ day and IVIG $(400 \mathrm{mg} / \mathrm{kg} /$ day $\times 5$ days $)$ were initiated. Because a sufficient decrease in the levels of muscle enzymes was not achieved, administration of tacrolimus ( $3 \mathrm{mg} /$ day $)$ was initiated 13 days after admission, and IVIG was performed twice more. The serum levels of muscle enzymes decreased to the reference range without the reactivation of $\mathrm{HCV}$.

\section{Discussion}

We experienced a patient who developed DM during IFN$\alpha$ therapy for hepatitis C. Eleven patients with PM/DM ( 8 with PM and 3 with DM) related to IFN- $\alpha$ therapy, including our patient, have been reported (Table 1) [5-14]. $\mathrm{PM} / \mathrm{DM}$ related to IFN- $\alpha$ therapy is more frequent in males. The diseases for which IFN- $\alpha$ therapy was indicated in these patients included hepatitis $\mathrm{C}$ in 6 patients, malignant melanoma in 2, hepatitis B in 1, essential thrombocytosis in 1 , and chronic myelocytic leukemia in 1 . Most patients, including our patient, developed PM/DM within 3 months after the start of IFN- $\alpha$ therapy that ranged from 2 weeks to 7 months in duration. Two previously reported patients with DM were positive for anti-ARS antibodies, such as anti-Jo-1 and anti-PL-7 antibodies, and interstitial pneumonia was concomitantly present $[5,6]$. However, these findings were absent in our patient. The PM/DM related to IFN- $\alpha$ in these patients responded to treatment well with a favorable prognosis. In one patient, the discontinuation of IFN- $\alpha$ improved DM spontaneously without immunosuppressive treatment.

Re-administration of IFN- $\alpha$ should be considered cautiously. It was reported that re-administration of IFN- $\alpha$ caused rapid recurrence of myositis in a patient with inclusion body myositis related to IFN- $\alpha$ [17]. However, the discontinuation of IFN therapy in $\mathrm{HCV}$ carriers or the use of steroids in $\mathrm{HCV}$-infected patients may increase the RNA levels of HCV, causing hepatitis [18]. We could find no reports of reactivation of $\mathrm{HCV}$ or onset of hepatitis caused by discontinuation of IFN- $\alpha$ or start of immunosuppressive therapy in IFN- $\alpha$-related DM/PM patients with HCV infection. Reactivation of $\mathrm{HCV}$ in our patient was not observed despite strong immunosuppressive therapy with high-dose glucocorticoid and tacrolimus. However, therapeutic strategies for the reactivation of $\mathrm{HCV}$ or progression of hepatitis are not established, and care must be taken to avoid these risks. 
Type I IFN is involved in the pathogenesis of autoimmune diseases such as systemic lupus erythematosus and PM/DM [19-21]. A large number of plasmacytoid dendritic cells infiltrate into the muscle tissue of patients with $\mathrm{PM} / \mathrm{DM}$, and mRNAs of the type I IFN-associated gene (IFN signature) are highly expressed [22]. Myxovirusresistant protein A, a gene that is induced by type I IFN, is highly expressed in the muscle fibers and blood vessels of these patients [22, 23]. PM/DM as a complication of IFN$\alpha$, including that in the present patient, indicates that type I IFN may be involved in the onset of PM/DM, although the exact relation between type I IFN and the development of PM/DM as well as the potential mechanism of disease development remain unclear. These issues must be examined more thoroughly in the future.

We presented a patient who developed DM during the administration of IFN- $\alpha$ for treatment of hepatitis C. He was successfully treated with IVIG and tacrolimus in addition to glucocorticoid despite serious muscular symptoms. Several similar cases of PM/DM as a complication related to IFN- $\alpha$ have been reported. These cases suggest that IFN$\alpha$ may contribute to the pathogenesis of PM/DM.

\section{Conflict of interest None.}

Open Access This article is distributed under the terms of the Creative Commons Attribution License which permits any use, distribution, and reproduction in any medium, provided the original author(s) and the source are credited.

\section{References}

1. Kao L, Chung L, Fiorentino DF (2011) Pathogenesis of dermatomyositis: role of cytokines and interferon. Curr Rheumatol Rep 13:225-232

2. Saida T, Tashiro K, Itoyama $Y$ et al (2005) Interferon Beta-1b multiple sclerosis study group of Japan. Interferon beta- $1 \mathrm{~b}$ is effective in Japanese RRMS patients: a randomized, multicenter study. Neurology 64:621-630

3. Bohan A, Peter JB (1975) Polymyositis and dermatomyositis (first of two parts). N Engl J Med 292:344-347

4. Bohan A, Peter JB (1975) Polymyositis and dermatomyositis (second of two parts). N Engl J Med 292:403-407

5. Aouba A, Georgin-Lavialle S, Terrier B et al (2011) Anti-PL7 antisynthetase syndrome under interferon therapy. Joint Bone Spine 78:94-97
6. Dietrich LL, Bridges AJ, Albertini MR (2000) Dermatomyositis after interferon alpha treatment. Med Oncol 17:64-69

7. John A, El Emadi S, Al Kaabi S et al (2007) Polymyositis during pegylated alpha-interferon ribavirin therapy for chronic hepatitis. Indian J Gastroenterol 26:147-148

8. Matsuya M, Abe T, Tosaka M et al (1994) The first case of polymyositis associated with interferon therapy. Intern Med 33:806-808

9. Ferri C, La Civita L, Fazzi P et al (1996) Polymyositis, lung fibrosis, and cranial neuropathy in a patient with hepatitis $\mathrm{C}$ virus infection. Arthritis Rheum 39:1074-1075

10. Venezia G, Licata A, Di Marco V et al (2005) Acute polymyositis during treatment of acute hepatitis $\mathrm{C}$ with pegylated interferon alpha-2b. Dig Liver Dis 37:882-885

11. Lee SW, Kim KC, Oh DH et al (2002) A case of polymyositis with dilated cardiomyopathy associated with interferon alpha treatment for hepatitis B. J Korean Med Sci 17:141-143

12. Hengstman GJ, Vogels OJ, ter Laak HJ et al (2000) Myositis during long-term interferon-alpha treatment. Neurology 54:2186

13. Cirigliano G, Della Rossa A, Tavoni A et al (1999) Polymyositis occurring during alpha-interferon treatment for malignant melanoma: a case report and review of the literature. Rheumatol Int 19:65-67

14. Falcone A, Bodenizza CA, Musto P et al (1998) Symptomatic myopathy during interferon alpha therapy for chronic myelogenous leukemia. Leukemia 12:1329

15. Bonaci-Nikolic B, Jeremic I, Andrejevic S et al (2009) Antidouble stranded DNA and lupus syndrome induced by interferonbeta therapy in a patient with multiple sclerosis. Lupus 18:78-80

16. Sladkova V, Mares J, Lubenova B et al (2011) Drug-induced systemic lupus erythematosus in interferon beta-1b therapy. Neuro Endocrinol Lett 32:4-6

17. Warabi Y, Matsubara S, Mizutani T et al (2004) Inclusion body myositis after interferon-alpha treatment in a patient with HCV and HTLV-1 infection. Rinsho Shinkeigaku 44:609-614 [in Japanese]

18. Watt K, Veldt B, Charlton M (2009) A practical guide to the management of $\mathrm{HCV}$ infection following liver transplantation. Am J Transplant 9:1707-1713

19. Kyogoku C, Tsuchiya N (2007) A compass that points to lupus: genetic studies on type I interferon pathway. Genes Immun 8:445-455

20. Wenzel J, Schmidt R, Proelss J (2006) Type I interferon-associated skin recruitment of CXCR3 + lymphocytes in dermatomyositis. Clin Exp Dermatol 31:576-582

21. Greenberg SA (2007) Proposed immunologic models of the inflammatory myopathies and potential therapeutic implications. Neurology 69:2008-2019

22. Greenberg SA, Pinkus JL, Pinkus GS et al (2005) Interferonalpha/beta-mediated innate immune mechanisms in dermatomyositis. Ann Neurol 57:664-678

23. Baechler EC, Bauer JW, Slattery CA et al (2007) An interferon signature in the peripheral blood of dermatomyositis patients is associated with disease activity. Mol Med 13:59-68 